Revista Brasil. Bot., V.31, n.4, p.689-700, out.-dez. 2008

\title{
Morfoanatomia da plântula e tirodendro de Rollinia sylvatica (A. St.-Hil.) Mart. (Annonaceae)
}

\author{
JULIANA LISCHKA SAMPAIO MAYER ${ }^{1}$, ANA CRISTINA ATALA ALVES', \\ LUIZ ANTONIO DE SOUZA² e CLEUSA BONA ${ }^{1,3}$
}

(recebido: 24 de agosto de 2006; aceito: 11 de setembro de 2008)

\begin{abstract}
Rollinia sylvatica (A. St.-Hil.) Mart. (Annonaceae) seedling and tirodendro morphology and anatomy) Morphology and anatomy studies about seedling are important to identify species and to comprehend Angiosperm life cycle. However, there are few researches about it. The aim of this study is to analyze the morphological and anatomical aspects of the structure of Rollinia sylvatica (A. St.-Hil.) Mart seedlings, which is a native species from South of Brazil. The seedlings were obtained from seeds collected in Antonina, state of Paraná. The germination was carried out in a green house condition. Seedlings and tirodendros were collected 2, 4, 8, 18, 40 e 55 days after germination and were fixed in FPA 50. These plants are phanerocotylars and epigeous with tap and diarch root. The hypocotyl has transition structure between root and stem, being separated and spreading cells from primary xylem, arranged around of parenchyma pith. Phloem keeps undivided. At the beginning of epicotyls two vascular bundles are formed. The 55 day old seedlings secondary growth is notorious in the root basal region, hypocotyl and epicotyl. Cotyledons, eophylls and metaphylls present uniseriate epidermis on both faces. Cotyledons are amphihypostomatic and eophylls and metaphylls are hypostomatic, all of them have dorsiventral mesophyll. The cotyledon midrib is not prominent with a bundle. The midrib is prominent and it has five collaterals bundle in the eophyll and seven in the metaphyll. The three leaves have different petiole formats, subepidermic collenchyma, two collateral vascular bundles ones in the cotyledon and ten in the eophyll and metaphyll.
\end{abstract}

Keywords - anatomy, araticum, morphology, seedling

RESUMO - (Morfoanatomia da plântula e tirodendro de Rollinia sylvatica (A. St.-Hil.) Mart. (Annonaceae)). O estudo morfoanatômico de plântulas é importante para a identificação das espécies e para a compreensão do ciclo de vida das Angiospermae. Entretanto, trabalhos sobre o tema são raros. O objetivo dessa investigação é analisar a estrutura morfoanatômica de plântulas e tirodendros de Rollinia sylvatica (A. St.-Hil.) Mart, espécie nativa da região sul do Brasil. As sementes foram coletadas no Município de Antonina-PR e germinadas em casa de vegetação. As plântulas e tirodendros foram coletados com 2, 4, 8, 18, 40 e 55 dias após a germinação e fixados em FPA 50. As plântulas são fanerocotiledonares e epígeas. A raiz é pivotante e diarca. O hipocótilo tem estrutura de transição entre raiz e caule, com separação e afastamento das células do xilema primário, que passam a se dispor ao redor da medula parenquimática; o floema permanece indiviso. No início do epicótilo formam-se dois feixes vasculares tipicamente caulinares. No tirodendro de 55 dias o crescimento secundário é evidente na região basal da raiz, hipocótilo e epicótilo. Os cotilédones, eofilos e metafilos apresentam epiderme unisseriada em ambas as faces. Os cotilédones são anfi-hipoestomáticos e os eofilos e metafilos são hipoestomáticos, todos com mesofilo dorsiventral. A nervura central é não proeminente com um feixe no cotilédone e proeminente com cinco feixes colaterais no eofilo e sete no metafilo. O pecíolo tem formato diferente nas três folhas, com colênquima subepidérmico e dois feixes vasculares colaterais no cotilédone e dez no eofilo e metafilo.

Palavras-chave - anatomia, araticum, morfologia, plântula,

\section{Introdução}

A família Annonaceaeé composta por aproximadamente 130 gêneros, tem distribuição predominantemente tropical em todo o mundo, seus representantes são plantas lenhosas, de porte arbóreo ou arbustivo (Souza

1. Universidade Federal do Paraná, Setor de Ciências Biológicas, Departamento de Botânica, 81531-990, Curitiba, PR, Brasil

2. Universidade Estadual de Maringá, Centro de Ciências Biológicas, Departamento de Biologia, Av. Colombo, 5790 Zona 7, 87020-900 Maringá, PR, Brasil

3. Autor para correspondência: cleusabona@ufpr.br
\& Lorenzi 2005). Rollinia sylvatica (A. St.-Hil.) Mart é uma espécie nativa do Brasil, ocorrendo em Minas Gerais, e de São Paulo ao Rio Grande do Sul. É conhecida vulgarmente como araticum, araticum-do-mato, embira, cortiça e cortiça-amarela (Lorenzi 1998). Rollinia sylvatica é espécie de matas secundárias iniciais, desenvolvendo-se em clareiras pequenas ou mais raramente no sub-bosque (Paula et al. 2004).

A identificação taxonômica de plantas a partir de plântulas é uma tarefa difícil, uma vez que os caracteres externos e internos nos estádios iniciais de desenvolvimento podem ser diferentes daqueles observados nos indivíduos 
adultos (Pinheiro 1989). Mussury (2003), em seu trabalho de heterofilia juvenil nas Amaranthaceae, cita a morfologia e anatomia das folhas juvenis como uma importante ferramenta para o entendimento da complexidade estrutural exibida nos metafilos, além de auxiliar estudos taxonômicos e ecológicos. Mussury (2006) também enfatiza sobre a carência e importância das informações de morfologia das plântulas e morfoanatomia de cotilédones e eofilos, já que normalmente, os estudos enfocam somente a anatomia dos metafilos. Segundo Parra (1984) e Souza \& Oliveira (2004), características morfológicas de sementes e plântulas são importantes para seu reconhecimento na mata. A identificação de espécies nessas fases é essencial para se estabelecer a dinâmica de populações e seu manejo silvicultural (Silva et al. 1988). Batillani et al. (2006) concluíram que os aspectos morfológicos dos frutos, sementes, plântulas e plantas jovens de Maclura tinctoria podem facilitar a identificação da espécie e o reconhecimento das formas juvenis em ambientes naturais. Segundo Lima-Brito et al. (2006), que estudaram a semente e plântulas de três espécies de Annona, os aspectos morfológicos das plântulas podem ser seguramente empregados tanto em estudos taxonômicos como ecológicos. Esses autores ainda sugerem novos estudos com maior número de espécies para fornecer subsídios a trabalhos taxonômicos, filogenéticos e ecológicos do gênero Annona.

$\mathrm{O}$ estudo da morfologia das plantas nas primeiras fases de desenvolvimento permite a observação de estruturas transitórias, as quais desaparecem com a passagem para a fase adulta (Ricardi et al. 1977). De acordo com Mourão et al. (2002), na literatura botânica brasileira encontram-se trabalhos de morfologia de plântulas de espécies nativas, porém são raros os trabalhos com estudos anatômicos. Isso dificulta a compreensão do processo de desenvolvimento estrutural, fisiológico e ecológico de plantas florestais nos seus estádios iniciais. Além disso, estudos anatômicos em Annonaceae são pouco explorados (Van Setten \& Koek-Noorman 1986), até os dias atuais.

$\mathrm{O}$ desmatamento indiscriminado tem provocado a extinção de diversas espécies vegetais e colocado outras em risco. A conservação e a reconstituição de florestas tropicais dependem da compreensão da ecologia tropical, a qual está atrelada a estudos que permitam a precisa identificação das espécies vegetais a partir de suas fases juvenis (Oliveira 2001). Segundo Souza \& Oliveira (2004), apesar da situação crítica de desmatamento no Estado do Paraná, os trabalhos sobre morfologia de plântulas são restritos.

O presente trabalho visa, portanto, o estudo morfoanatômico de plântulas e tirodendros de Rollinia sylvatica, para auxiliar na sua identificação em estádio inicial de desenvolvimento e contribuir para estudos taxonômicos, filogenéticos e ecológicos.

\section{Material e métodos}

As sementes de Rollinia sylvatica foram coletadas no Município de Antonina - PR, na reserva Natural do Cachoeira. Germinaram em casa de vegetação do Departamento de Botânica da UFPR (Universidade Federal do Paraná), com nebulização intermitente de 15 segundos a cada 30 minutos. A temperatura média foi de $24,7{ }^{\circ} \mathrm{C}$ no interior da estufa. As sementes foram colocadas em sacos com $22 \mathrm{~cm}$ de altura e $14 \mathrm{~cm}$ de diâmetro com o substrato comercial PlantMax ${ }^{\circledR}$ (para hortaliças). As plântulas foram coletadas com 2, 4, 8 e 18 dias após a germinação, marcada pela protusão da radícula e os tirodendros com 40 e 55 dias. O metafilo foi coletado do tirodendro com seis meses de idade. As amostras foram fixadas em FPA 50 (álcool 50\%, ácido propiônico e formaldeído, 90:5:5) (Johansen 1940).

Para a análise anatômica qualitativa foram coletadas amostras aos 4 e 55 dias, das seguintes regiões: raiz, hipocótilo, transição hipocótilo-epicótilo, epicótilo e região mediana do pecíolo e limbo do cotilédone e eofilo. Do tirodendro, aos seis meses de idade, foi coletada a região mediana do pecíolo e limbo dos primeiros metafilos. Os metafilos foram definidos por manter as características anatômicas constantes. Essas amostras foram destinadas à preparação de lâminas permanentes, sendo incluídas em historresina (GMA-glicol metacrilato), segundo a técnica de Feder \& O'brien (1968) e indicações do fabricante. O material botânico foi seccionado em micrótomo de rotação, e os cortes foram obtidos com $7 \mathrm{~mm}$ de espessura e corados com azul de toluidina (Feder \& O'Brien 1968). As lâminas foram montadas com resina sintética (Permalte ${ }^{\circledR}$ ). As fotomicrografias foram realizadas em microscópio Zeiss com câmera digital Sony Cyber-shot $\mathrm{P} 72^{\circledR}$ acoplada.

A terminologia adotada para descrever a fase inicial do desenvolvimento de Rollinia sylvatica baseou-se em Souza (2003). Dessa forma, plântula é considerada a fase desde a germinação da semente até a formação da primeira folha ou eofilo e tirodendro a fase que compreende o final do desenvolvimento do primeiro eofiolo na plântula até o momento que surgem os primeiros nomofilos ou metafilos. A classificação dos tipos de estômatos e a descrição da morfologia foliar foi efetuada com base na classificação proposta por Ash et al. (1999).

Testes microquímicos foram realizados em secções do terço médio dos cotilédones e eofilos, através de cortes à mão livre, com auxílio de lâmina de barbear. A ocorrência de compostos lipídicos foi evidenciada pelo Sudan III (Johansen 1940) e amido pelo Lugol (Berlyn \& Miksche 1976).

A epiderme da região mediana dos cotilédones, eofilo e metafilo foi isolada através do processo de maceração de acordo com a técnica de Franklin (1945). Em seguida, o 
material foi lavado e corado com safranina a $1 \%$ em solução aquosa, sendo montado em gelatina glicerinada (O’Brien \& Mccully 1981) e vedado com esmalte de unha incolor (Dop \& Gautié 1928).

\section{Resultados e discussão}

A germinação é epígea e teve início 50 dias após a semeadura. $\mathrm{O}$ desenvolvimento da raiz e do hipocótilo é relativamente rápido, sendo observados nas plântulas com quatro dias (figuras 1-4). Na plântula de 18 dias o hipocótilo apresenta-se alongado e verde, a raiz pivotante possui muitas ramificações e os cotilédones, completamente expandidos, são foliáceos, delgados e fotossintetizantes (figura 5). No tirodendro com 55 dias é possível observar os cotilédones opostos e os eofilos alternados no caule (figura 6). Segundo Duke (1965), plântulas com os cotilédones expostos são denominadas de fanerocotiledonares. Ressel et al. (2004) afirmam que plântulas fanero-epígeo-foliáceas apresentam como vantagem na competição por espaço e luz, a presença de cotilédones prontamente fotossintetizantes, o que é característica de espécies de estádios sucessionais iniciais. Lima-Brito et al. (2006) observaram que, em três espécies de Annona (Annonaceae), houve diferentes tipos de germinação, em A. crassiflora e A. squamosa a germinação foi epígeo-fanerocotiledonar e em $A$. muricata foi hipógea-criptocotiledonar. Demonstrando que a germinação epígeo-fanerocotiledonar não pode ser estrapolada para o gênero Annona.

A raiz principal é diarca e protostélica do ápice até a base. A epiderme unisseriada e o córtex parenquimático são observados desde o crescimento inicial das plântulas até o crescimento secundário inicial (figura 7). $\mathrm{O}$ hipocótilo, na plântula com quatro dias de idade, apresenta estrutura de transição entre raiz e caule, caracterizada pela separação e afastamento das células do xilema primário, que passam a se dispor ao redor da medula parenquimática; o floema, por sua vez, permanece indiviso (figuras 8-10). Souza \& Oliveira (2004), observaram a mesma disposição do protoxilema e metaxilema na estrutura de transição, nas espécies Tabebuia avellanedae e T. chrysotricha. A forma de transição observada no hipocótilo de Rollinia sylvatica está de acordo com a teoria de Van Tieghem \& Chauveaud citada por Strasburger et al. (1953), na qual os autores afirmam que os cordões de floema correm retilíneos da raiz para o caule, mas o xilema se divide e sofre um giro de $180^{\circ}$, colocando-se por dentro dos cordões de floema vizinho, para a maioria das dicotiledôneas. O conceito de que o hipocótilo seja uma região de transição é aceita por vários autores, como Esau (1959), Mauseth (1988) e Fahn (1990).

Aos 55 dias, o crescimento secundário é evidente na região do hipocótilo e epicótilo (figuras 11-14). O hipocótilo, em secção transversal, tem contorno circular com instalação da periderme (figuras 11-12). No floema primário há uma calota de fibras externa e no floema secundário as células parenquimáticas e elementos de tubo crivado são intercaladas por camadas de fibras. $\mathrm{O}$ xilema secundário é separado do floema por uma faixa cambial contínua e é constituído de vasos de diferentes calibres, parênquima axial e raios parenquimáticos. $\mathrm{O}$ xilema primário é visível junto à medula parenquimática. No nó cotiledonar o traço do cotilédone possui dois feixes e é unilacunar (figura 13). Na região axilar de cada cotilédone ocorre uma gema recoberta por tricomas (figura 13). $\mathrm{O}$ epicótilo possui menor diâmetro que o hipocótilo, epiderme unisseriada e córtex parenquimático. O cilindro central do epicótilo possui floema primário com calotas de fibras, floema secundário, câmbio vascular, xilema secundário desenvolvido e medula parênquimática. (figura 14). Células secretoras com conteúdo granuloso ocorrem no parênquima do córtex e do cilindro vascular em toda a planta.

Os eofilos (figura 6) e os metafilos, são folhas simples, desenvolvem-se alternadamente no caule e são morfologicamente semelhantes mas diferem anatomicamente. Os primeiros metafilos surgem após seis meses da germinação no sétimo ou oitavo nós, nessa fase a planta tem em torno de um metro de altura e mantém a filotaxia alterna dística. Folhas simples, alternas e dísticas são típicas em Annona de acordo com Lobão et al. (2005). Segundo Lima-Brito et al. (2006) plântulas de Annona crassiflora, A. squamosa e A. muricata também apresentam os eofilos simples e alternos.

Tanto o eofilo quanto o metafilo apresentam formato elíptico com base convexa, ápice acuminado, margem inteira e venação semicraspedódroma de acordo com Ash et al. (1999). Já o cotilédone difere morfologicamente dos eofilos e metafilos por possuir formato ovalado, ápice convexo e venação reticulódroma (Ash et al. 1999).

As células epidérmicas do cotilédone, eofilo e metafilo, em vista frontal (figuras 15-20), são poligonais na face adaxial com paredes anticlinais retas a ligeiramente curvas (figuras 15, 17 e 19). Na face abaxial essas células são irregulares com paredes anticlinais sinuosas, sendo essa sinuosidade mais intensa no metafilo (figuras 16, 18 e 20). Idioblastos com drusas estão presentes na epiderme de ambas as faces de todas as folhas. Os estômatos são do tipo paracítico e são encontrados em ambas as faces no cotilédone, sendo anfi-hipoestomáticos segundo 


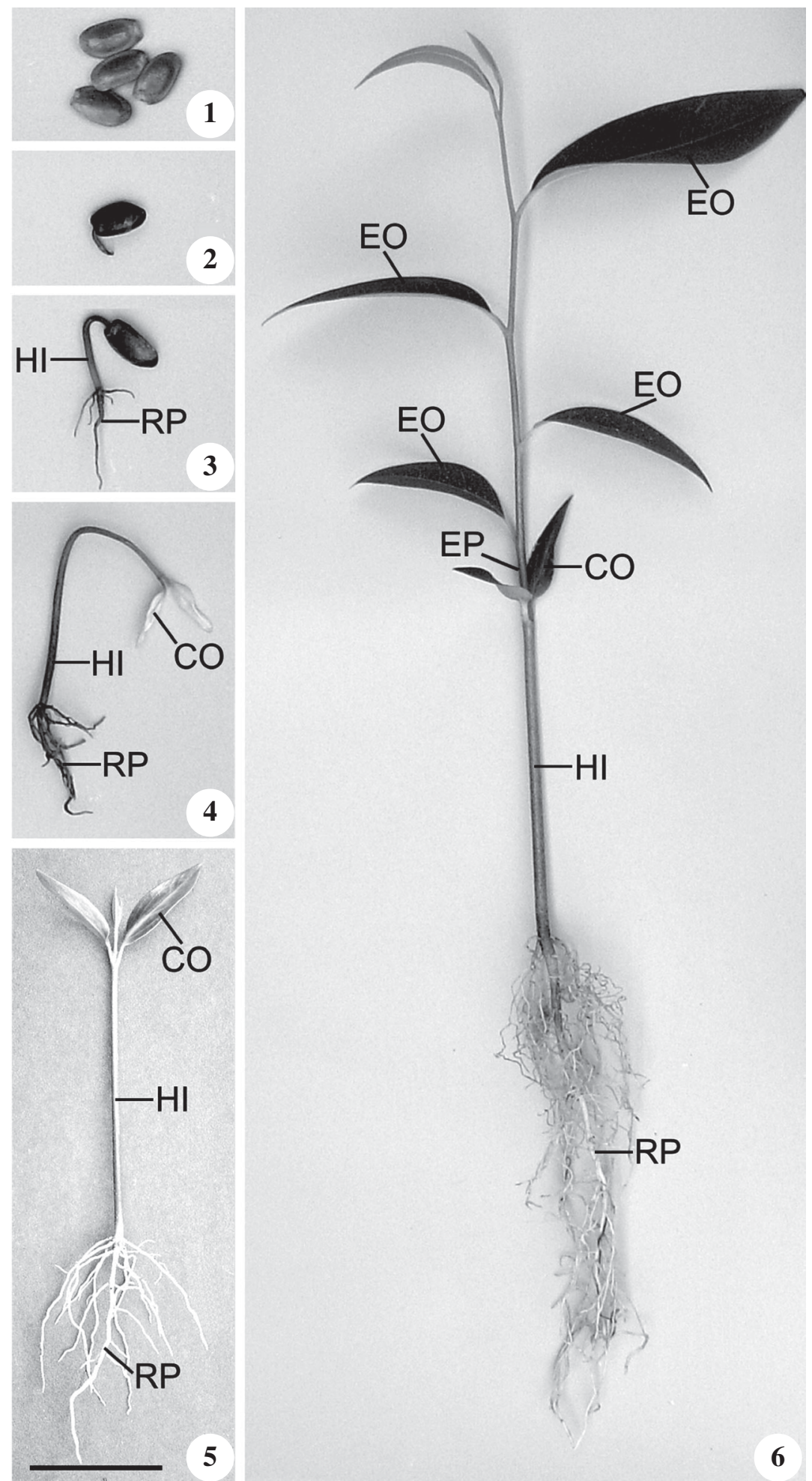

Figuras 1-6. Desenvolvimento de plântulas e tirodendro de Rollinia sylvatica. 1. Sementes. 2. Plântula com dois dias. 3. Plântula com quatro dias. 4. Plântula com oito dias. 5. Plântula com 18 dias. 6 . Tirodendro com 55 dias. $(\mathrm{CO}=$ cotilédone; $\mathrm{EO}=$ eofilo; $\mathrm{EP}=$ epicótilo; $\mathrm{HI}=$ hipocótilo; $\mathrm{RP}=$ raiz principal). Barra $=4 \mathrm{~cm}$.

Figures 1-6. Rollinia sylvatica seedling and tirodendro development. 1. Seeds. 2. Seedling two days old. 3. Seedlings four days old. 4. Seedling eight days old. 5. Seedling 18 days old. 6 . Tirodendro 55 days old. (CO = cotyledon; EO = eophyll; $\mathrm{EP}=$ epicotyl; $\mathrm{HI}=$ Hypocotyl; $\mathrm{RP}=$ main root $) . \mathrm{Bar}=4 \mathrm{~cm}$. 

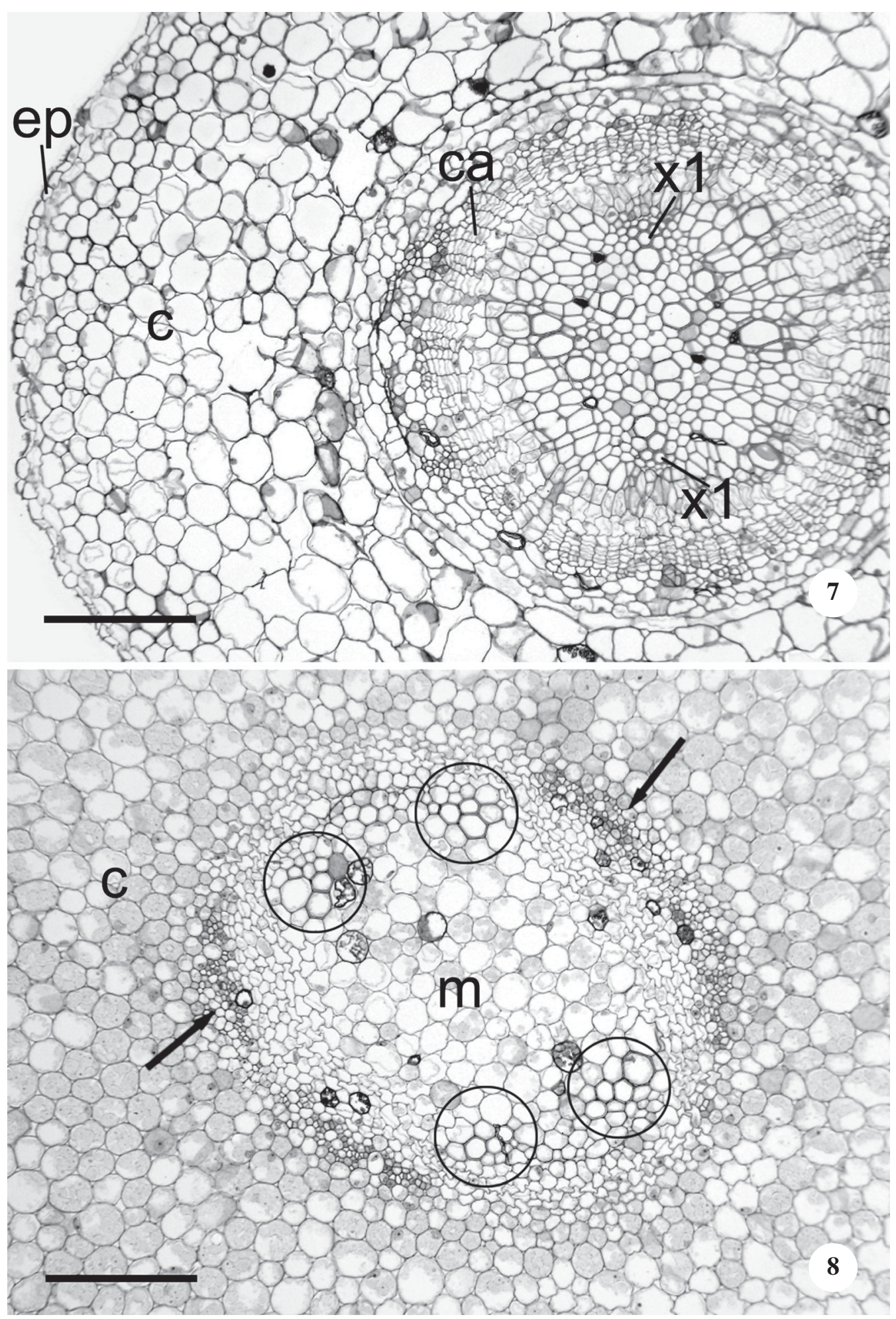

Figuras 7-8. Secções transversais da plântula de Rollinia sylvatica. 7. Raiz diarca quatro dias após a germinação. 8. Hipocótilo na porção basal quatro dias após a germinação. $(\mathrm{c}=$ cortex; $\mathrm{ca}=$ zona cambial; $\mathrm{ep}=$ epiderme; $\mathrm{m}=$ medula; $\mathrm{x} 1=$ xilema primário; seta $=$ floema; círculos $=$ xilema). Barra $=200 \mu \mathrm{m}$.

Figures 7-8. Transversal section of Rollinia sylvatica seedling. 7. Diarca root four days after germination. 8. Hypocotyl in the basal portion four days after germination. $(\mathrm{c}=$ cortex; $\mathrm{ca}=$ vascular cambium; $\mathrm{ep}=$ epidermis; $\mathrm{m}=$ pith; $\mathrm{x} 1=$ primary xylem; arrow $=$ phloem; circles $=$ xylem $)$. Bar $=200 \mu \mathrm{m}$. 

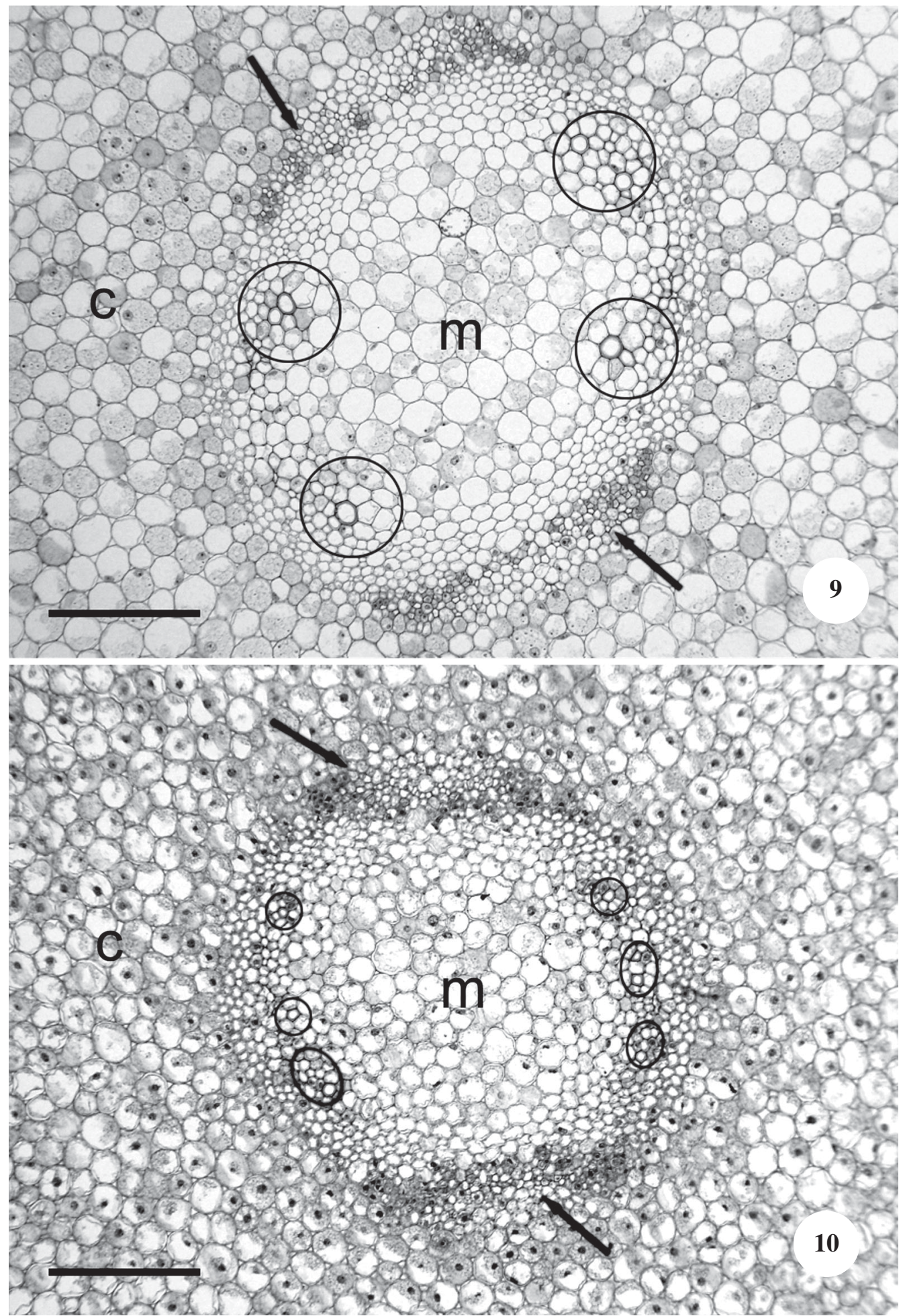

Figuras 9-10. Secções transversais da plântula de Rollinia sylvatica. 9. Hipocótilo na porção mediana quatro dias após a germinação. 10. Hipocótilo na porção apical (logo abaixo da inserção dos cotilédones) quatro dias após a germinação. $(\mathrm{c}=$ cortex $; \mathrm{m}=$ medula; seta $=$ floema; círculos $=$ xilema $)$. Barra $=200 \mu \mathrm{m}$.

Figures 9-10. Transversal section of Rollinia sylvatica seedling. 9. Hypocotyl in the intermediary portion four days after germination. 10. Hypocotyl in the apical portion (It is locate under cotyledons insertion) four days after germination. $(\mathrm{c}=$ cortex $; \mathrm{m}=$ pith; arrow $=$ phloem; circles $=\mathrm{xylem}) . \mathrm{Bar}=200 \mu \mathrm{m}$. 

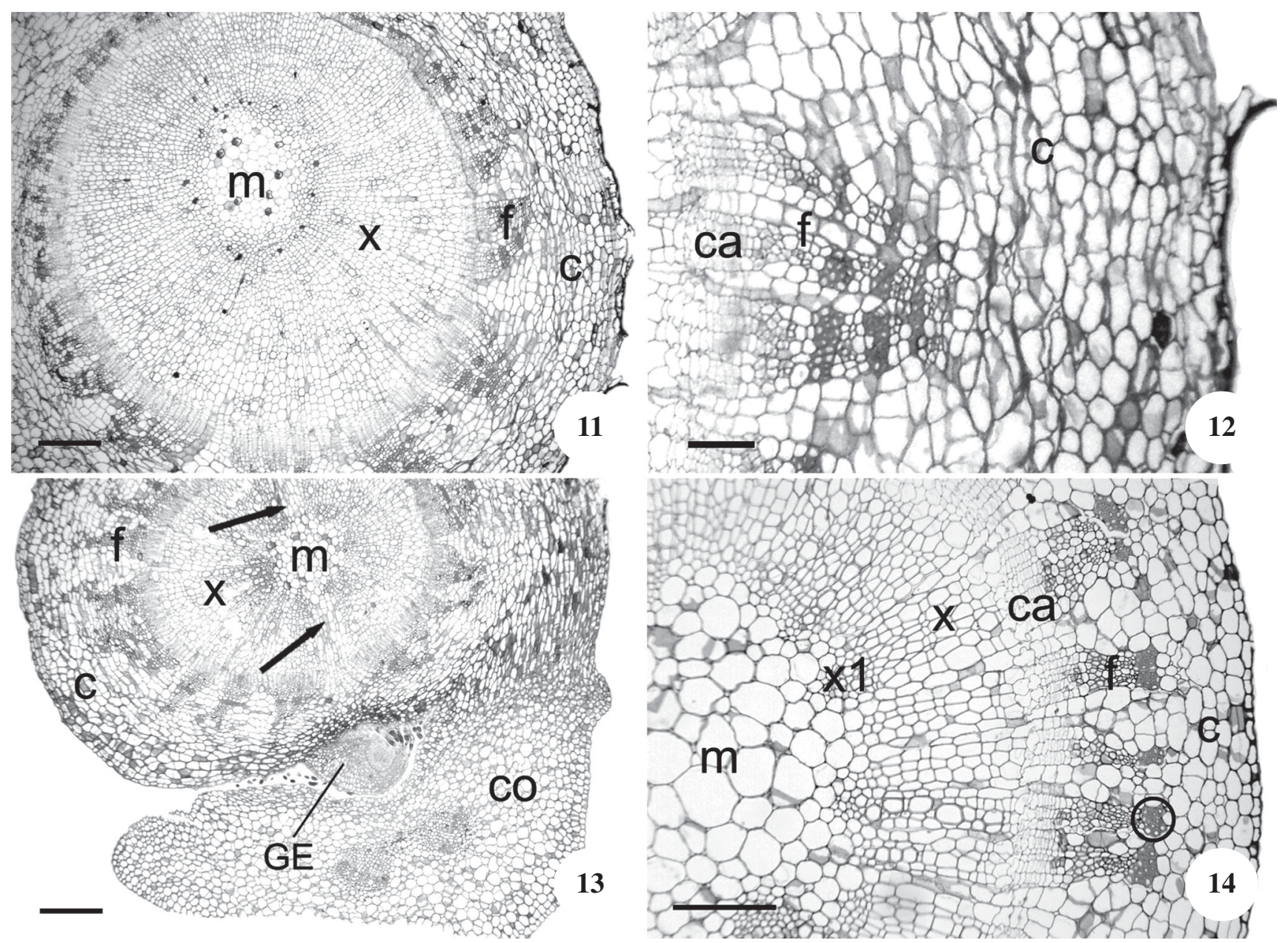

Figuras 11-14. Secções transversais do tirodendro de Rollinia sylvatica. 11. Hipocótilo na porção basal 55 dias após a germinação. 12. Detalhe do hipocótilo na porção basal 55 dias após a germinação. 13. Hipocótilo na porção apical (na região de inserção dos cotilédones) 55 dias após a germinação. 14. Epicótilo 55 dias após a germinação. $(\mathrm{c}=\mathrm{cortex}$; $\mathrm{ca}=$ zona cambial; $c 0$ = cotilédone; $\mathrm{f}=$ floema; $\mathrm{ge}=$ gema lateral; $\mathrm{m}=$ medula; $\mathrm{x}=$ xilema secundário; $\mathrm{x} 1$ = xilema primário; círculo = fibras; seta $=$ lacuna foliar). Barra $=300 \mu \mathrm{m}(11,13-14) ; 100 \mu \mathrm{m}(12)$.

Figures 11-14. Transversal section of Rollinia sylvatica tirodendro. 11. Hypocotyl in the basal portion 55 days after germination. 12. Detail of hypocotyl in the basal portion 55 days after germination. 13. Hypocotyl in the apical portion (It is located in the region of cotyledons insertion) 55 days after germination. 14. Epicotyl 55 days after germination. $(\mathrm{c}=$ cortex; $\mathrm{ca}=$ vascular cambium; $\mathrm{co}=$ cotyledon; $\mathrm{f}=$ phloem; $\mathrm{ge}=$ lateral bud; $\mathrm{m}=$ pith; $\mathrm{x}=$ secundary $\mathrm{xylem} ; \mathrm{x} 1$ = primary $\mathrm{xylem}$; circles $=$ fibre; arrow $=$ left lacuna). $B a r=300 \mu \mathrm{m}(11,13-14) ; 100 \mu \mathrm{m}(12)$.

a classificação de Napp-Zinn (1973, 1974), e somente na face abaxial no eofilo e metafilo, sendo classificados como hipoestomáticos. Metcalfe \& Chalk (1950) e Watson \& Dallwitz (2000) observaram que nas plantas da família Annonaceae as folhas apresentam estômatos paracíticos somente na face abaxial da folha. Folhas de Xylopia brasiliensis (Annonaceae), segundo Justo et al. (2005), também apresentam estômatos paracíticos na face abaxial e presença de drusas nas células epidérmicas; no entanto, as drusas só foram observadas nas células da face adaxial. Além disso, ambas as faces apresentavam células de formato irregular com paredes anticlinais sinuosas, diferentemente do observado em Rollinia sylvatica.

Em secção transversal, os cotilédones, eofilos e metafilos e apresentam epiderme unisseriada em ambas as faces e mesofilo dorsiventral (figuras 21-26). As células da epiderme da face adaxial são mais volumosas que as células da face abaxial. O teste com Sudam III identificou fina cutícula no cotilédone, eofilo e metafilo. 


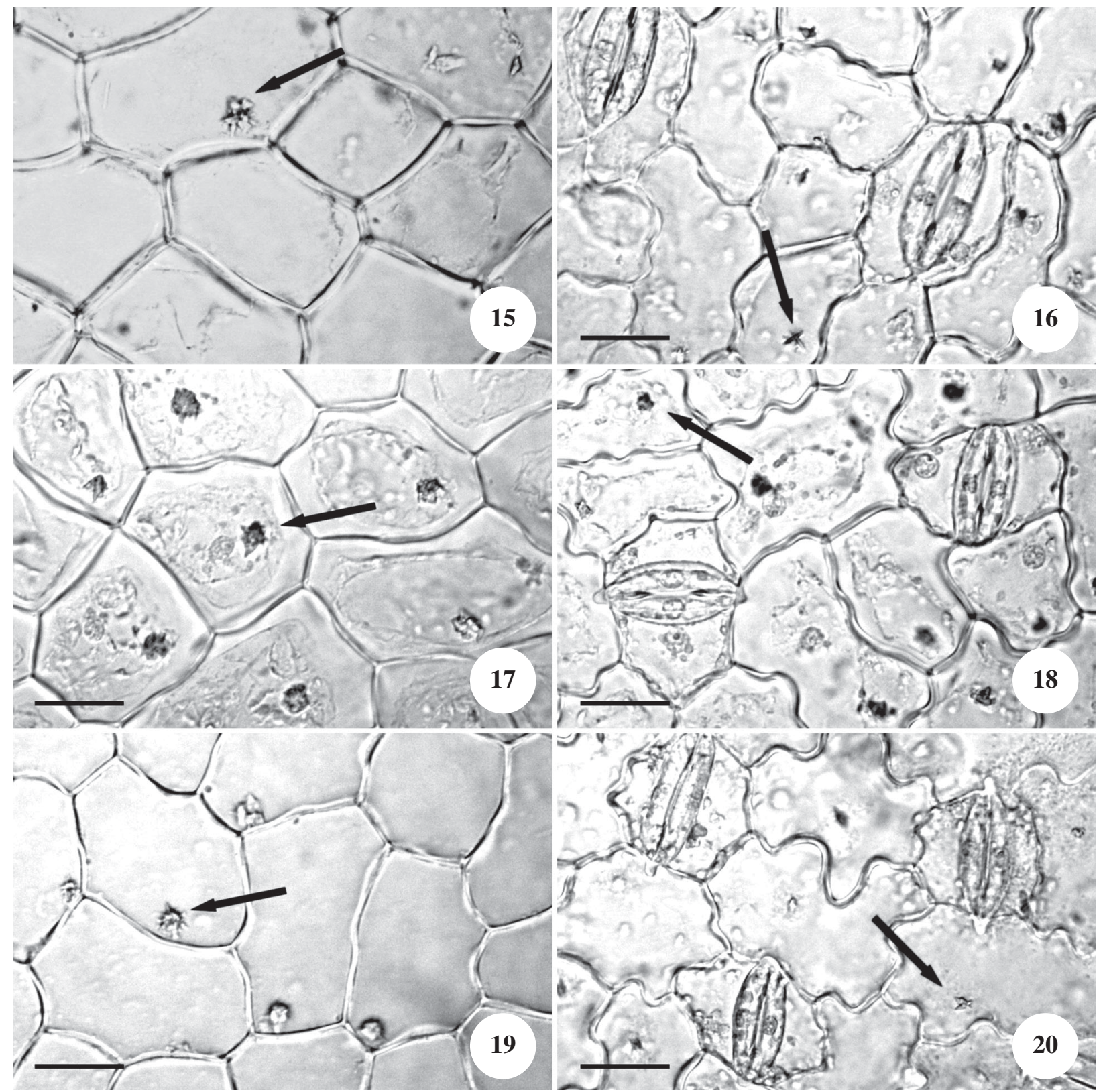

Figuras 15-20. Secções paradérmicas de folhas de Rollinia sylvatica. 15. Face adaxial da epiderme do cotilédone. 16. Face abaxial da epiderme do cotilédone. 17. Face adaxial da epiderme do eofilo. 18. Face abaxial da epiderme do eofilo. 19. Face adaxial da epiderme do metafilo. 20. Face abaxial da epiderme do metafilo. (seta $=$ drusas). Barra $=100 \mu \mathrm{m}$.

Figures 15-20. Paradermic section of Rollinia sylvatica leaves. 15. Adaxial face of cotyledon epidermis. 16. Abaxial face of cotyledons epidermis. 17. Adaxial face of eophyll epidermis. 18. Abaxial face of eophyll epidermis. 19. Adaxial face of metaphyll epidermis. 20. Abaxial face of metaphyll epidermis. (arrow $=$ druses). Bar $=100 \mu \mathrm{m}$.

O parênquima paliçádico é constituído por uma única camada de células colunares justapostas tanto no cotilédone como no eofilo e metafilo (figuras 21, 23 e 25). Já o parênquima lacunoso é constituído por células de formato irregular com grandes espaços intercelulares, com sete a oito camadas no cotilédone e metafilo e quatro a cinco no eofilo. A menor quantidade de camadas de parênquima lacunoso reflete na menor espessura do eofilo em relação às outras folhas. Segundo Justo et al. (2005) Xylopia brasiliensis (Annonaceae) possui parênquima lacunoso formado por células com prolongamentos braciformes, arranjadas frouxamente, o que é semelhante ao mesofilo 

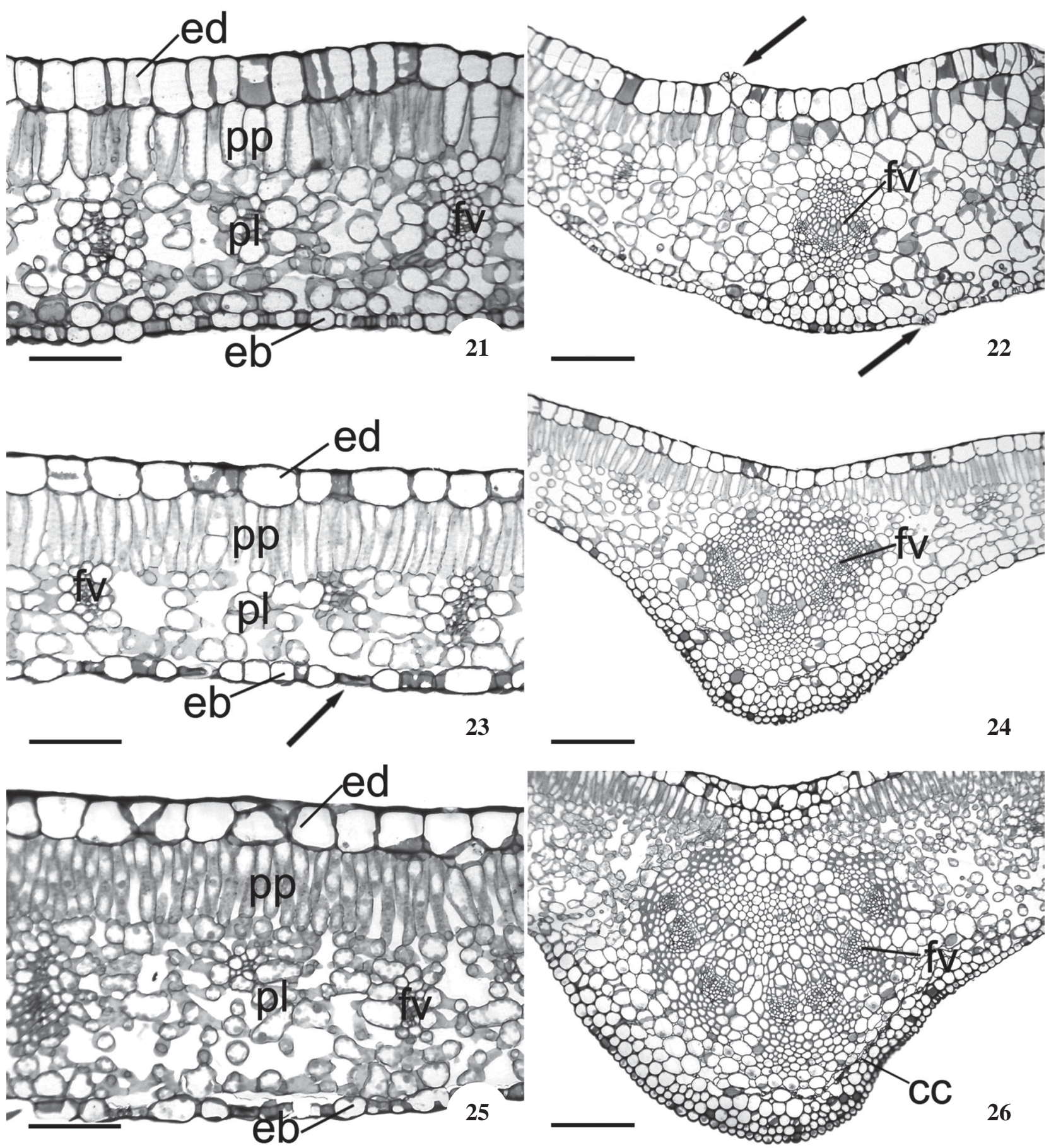

Figuras 21-26. Secções transversais de folhas de Rollinia sylvatica. 21. Região do limbo do cotilédone. 22. Região da nervura central do cotilédone. 23. Região do limbo do eofilo. 24. Região da nervura central do eofilo. 25. Região do limbo do metafilo. 26. Região da nervura central do metafilo. ( $c c=$ células colapsadas; eb = epiderme da face abaxial; ed = epiderme da face adaxial; $\mathrm{fv}=$ feixe vascular; $\mathrm{pl}=$ parenquima lacunoso; $\mathrm{pp}=$ parenquima paliçádico; seta = estômato). Barra $=100 \mu \mathrm{m}$ (21, 23 e 25$) ; 200 \mu \mathrm{m}(22,24$ e 26$)$.

Figures 21-26. Transversal sections of Rollinia sylvatica leaves. 21. Region of cotyledon blade. 22. Region of central vein cotyledon. 23. Region of eophyll blade. 24. Region of eophyll central vein. 25. Region of metaphyll blade. 26. Region of metaphyll central vein. ( $c c=$ collapsed cells; $\mathrm{eb}=$ lower epidermis; $\mathrm{ed}=$ upper epidermis; $\mathrm{fv}$ = bundle; $\mathrm{pl}$ = spongy parenchyma; $\mathrm{pp}=$ palisade parenchyma; arrow $=$ stomata $) . \mathrm{Bar}=100 \mu \mathrm{m}(21,23$ e 25$) ; 200 \mu \mathrm{m}(22,24$ e 26). 
do eofilo, metafilo e cotilédone da espécie estudada. Os testes microquímicos com Lugol foram positivos para amido no cotilédone, metafilo e eofilo, estando de forma esparsa no parênquima paliçádico.

A nervura central com um feixe vascular no cotilédone não é proeminente e no eofilo e metafilo é proeminente com cerca de cinco e sete feixes colaterais consecutivamente, a endoderme não é distinta do tecido circundante em nenhuma das três folhas (figuras 22, 24 e 26). Segundo Mourão et al. (2002), os metafilos diferem pouco morfologicamente dos eofilos em Trichilia catigua, T. elegans e T. pallida (Meliaceae), exceto anatomicamente pela maior dimensão dos feixes vasculares. Em metafilos de Xylopia brasiliensis (Annonaceae) a nervura central apresentou feixe vascular único colateral circundado por uma bainha contínua de fibras lignificadas (Justo et al., 2005). Na nervura central do eofilo e do metafilo é observada uma faixa de células colapsadas próximas a face abaxial da epiderme. Essa característica também foi observada por Albarello et al. (2001) em Rollinia тисоsa Jacq. Baill., considerada de valor diagnóstico para o gênero.

O pecíolo, em secção transversal, tem formato diferente nas três folhas, no cotilédone é de formato lenticular (figura 27), no eofilo é arredondado na face abaxial com duas proeminências na face adaxial (figura 28) e no metafilo é arredondado com duas projeções de pequeno porte na face adaxial (figura 29). No cotilédone as células epidérmicas da face adaxial são maiores que as da face abaxial. A epiderme do pecíolo do eofilo e metafilo, em secção transversal, é homogênea em toda circunferência. Os feixes vasculares presentes nos três pecíolos são do tipo colateral, sendo dois feixes no cotilédone, sete a oito no eofilo e nove a dez no metafilo (figuras 27-29).

Com os resultados obtidos foi possível observar que os caracteres morfoanatômicos durante a germinação e o desenvolvimento de Rollinia sylvatica são constantes e homogêneos. Esses caracteres possibilitam o reconhecimento da espécie na fase de plântula ou tirodendro no campo, tais como: germinação epígea, plântula fanerocotiledonar, cotilédones com filotaxia oposta, eofilos e metafilos com filotaxia alterna dística e presença de idioblastos com drusas na epiderme de ambas as faces do cotilédone, eofilo e metafilo. Devido à semelhança morfológica entre eofilos e metafilos, estes são diferenciados anatomicamente. $\mathrm{Na}$ transição dos eofilos para os metafilos há um aumento da complexidade no sistema vascular e na espessura do órgão. Os caracteres anatômicos são úteis para a taxonomia do grupo e para realizar inferências filogenéticas entre os gêneros. No entanto, são necessários novos estudos para o gênero

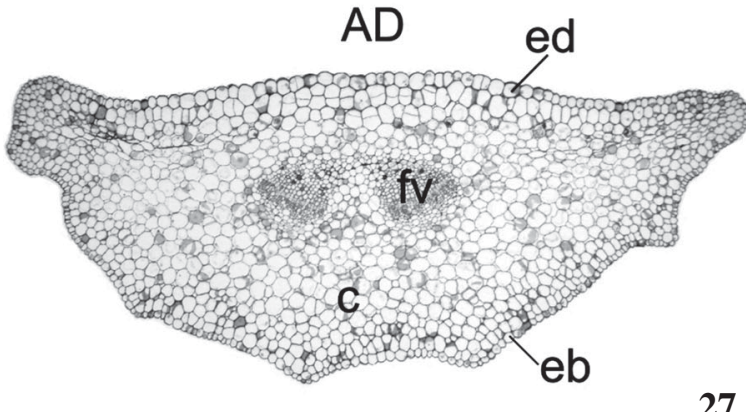

27

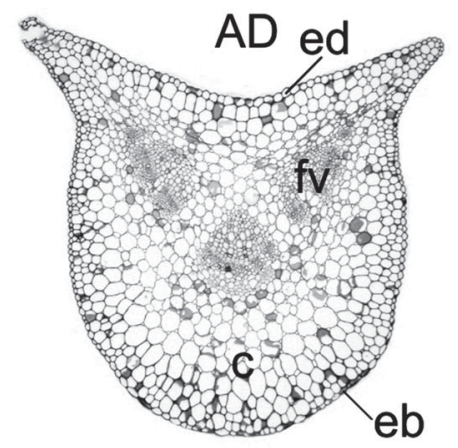

28

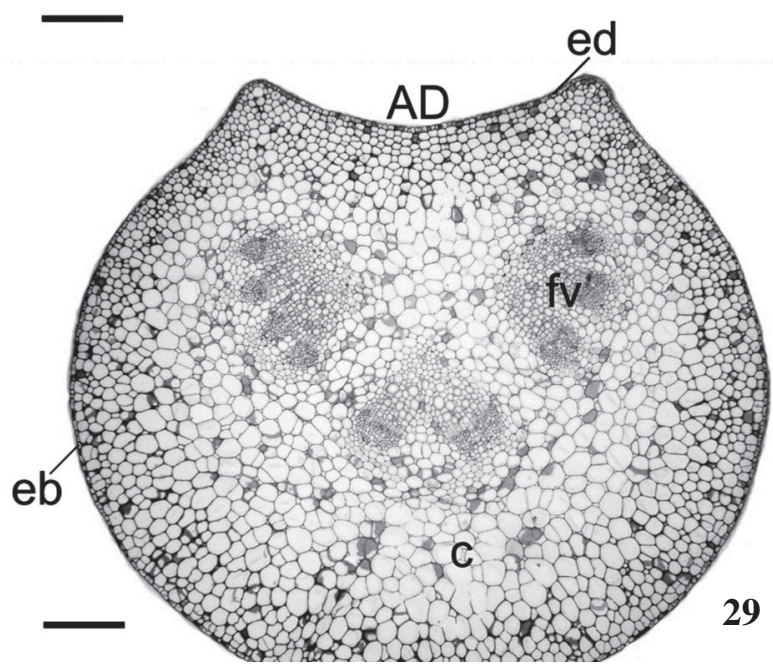

Figuras 27-29. Secções transversais de folhas de Rollinia sylvatica. 27. Pecíolo do cotilédone. 28. Pecíolo do eofilo. 29. Pecíolo do metafilo. $(\mathrm{AD}=$ face adaxial; $\mathrm{c}=$ cortex; $\mathrm{eb}=$ epiderme da face abaxial; $\mathrm{ed}=$ epiderme da face adaxial; $\mathrm{fv}=$ feixe vascular). Barra $=200 \mu \mathrm{m}$.

Figures 27-29. Transversal sections of Rollinia sylvatica leaves. 27. Petiole of cotyledon. 28. Petiole of eophyll. 29. Petiole of metaphyll. $(\mathrm{AD}=$ adaxial side; $\mathrm{c}=$ cortex; $\mathrm{eb}=$ lower epidermis; ed $=$ upper epidermis; $\mathrm{fv}=$ vascular bundle). $\mathrm{Bar}=$ $200 \mu \mathrm{m}$. 
Rollinia, principalmente estudos morfoanatômicos de plântulas até tirodendro.

Agradecimento - Os autores agradecem a Dri ${ }^{\mathrm{a}}$ Márcia Mendes Marques do Departamento de Botânica da Universidade Federal do Paraná por ter fornecido e identificado o material vegetal.

\section{Referências bibliográficas}

ALBARELLO, N., FIGUEIREDO, S.F.L., VIANA, V.R.C. \& NEVES, L.J. 2001. Anatomia foliar de Rollinia mucosa Jacq. Baill. (Annonaceae) sob condições de cultivo in vivo e in vitro. Revista Brasileira de Plantas Medicinais 4:35-46.

ASH, A., ELLIS, B., HICKEY, L.J., JOHNSON, K., WILF, P. \& WING, S. 1999. Manual of leaf Architecture morphological description and categorization of dicotyledonous and net-veined monocotyledonous angiosperms by Leaf Architecture Working Group. Smithsonian Institution, Washington. Disponível em http://www.yale.edu/peabody/collections/pb/ MLAintro.pdf Acesso em 06/07/2006.

BATTILANI, J.L., SANTIAGO, E.F. \& SOUZA, A.L.T. de 2006. Morfologia de frutos, sementes e desenvolvimento de plântulas e plantas jovens de Maclura tinctoria (L.) D. Don. ex Steud. (Moraceae). Acta Botanica Brasilica 20:581-589.

BERLYN, G.P. \& MIKSCHE, J.P. 1976. Botanical Microtechnique and Cytochemistry. The Iowa state Press, Ames.

DOP, P. \& GAUTIÉ, A. 1928. Manual of Technique Botanique. Lamarre, Paris.

DUKE, J.A. 1965. Keys for the identification of seedlings of some proeminent woody species in eight forest types in Puerto Rico. Annals of the Missouri Botanical Garden 52:314-350.

ESAU, K. 1959. Anatomia Vegetal. Ediciones Omega, Barcelona.

FAHN, A. 1990. Plant Anatomy. $4^{\text {th }}$ ed. Pergamon Press, Oxford.

FEDER, N. \& O' BRIEN, T.P. 1968. Plant microtechnique: some principles and new methods. American Journal of Botany 55:123-142.

FRANKLIN, G.L. 1945. A rapid method of softening wood for microtome sectioning. Australian Journal of Botany 33:393-408.

JOHANSEN, D.A. 1940. Plant Microtechnique. McGraw Hill Book, New York.

JUSTO, C.F., SOARES, A.M., GAVILANES, M.L. \& CASTRO, E.M. de 2005. Plasticidade anatômica das folhas de Xylopia brasiliensis Sprengel (Annonaceae). Acta Botanica Brasílica 19:111-123.

LIMA-BRITO, A., BELLINTANI, M.C., RIOS, A.P. de S., SILVA, J.R. dos S. \& DORNELLES, A.L.C. 2006. Morfologia de fruto, semente e plântula de três espécies de Annona (Annonaceae). Sitientibus Série Ciências Biologicas 6:119-128.
LOBÃO, A.Q., ARAUJO, D.S.D. \& KURTZ, B.C. 2005. Anonaceae das restingas do estado do Rio de Janeiro, Brasil. Rodriguesia 56:85-96.

LORENZI, H. 1998. Árvores Brasileira. Manual de Identificação e Cultivo de Plantas Arbóreas do Brasil. Nova Odessa, São Paulo.

MAUSETH, J.D. 1988. Plant anatomy. Menlo Park, The Benjamin/CummingsPublishing Company, California.

METCALFE, C.R. \& CHALK, L. 1950. Anatomy of the dicotyledons: leaves, stem, and wood in taxonomy with notes on economic uses. Claredon Press, Oxford, v.1, p.387-397.

MOURÃO, K.S.M., DIAS-PINTO, D., SOUZA, L.A.de \& MOSCHETA, I.S. 2002. Morfoanatomia de plântula e do tirodendro de Trichilia catigua A. Juss., T. elegans A. Juss. E T. pallida Sw. (Meliaceae). Acta Scientiarum. Biological Sciences 24:601-610.

MUSSURY, R.M. 2003. Caracterização morfoanatômica dos órgãos vegetativos de Pfaffia glomerata (Spreng.) Pedersen 'ginseng-brasileiro' - Amaranthaceae. Tese de doutorado, Universidade Estadual Paulista Júlio de Mesquita Filho, Botucatu.

MUSSURY, R.M., SCALON, S. de P.Q., GOMES, A.A. \& BARROS, S.S.U. de 2006. Caracterização morfoanatômica de plântulas de Gomphrena elegans Mart. (Amaranthaceae). Acta Scientiarum. Biological Sciences 28:87-93.

NAPP-ZINN, K. 1973-74. Anatomie des Blates. II. Blattanatomie der Angiopermen. Handbuch der Pflanzenanatomie. Gebruder Borntraeger, Berlin, bd. VIII, n. 2A.

O'BRIEN, T.P. \& McCULLY, Y.E. 1981. The study of plants structure: principles and selected methods. Termercarphy, Melbourne.

OLIVEIRA, D.M.T. 2001. Morfologia comparada de plântulas e plantas jovens de leguminosas arbóreas nativas: espécies de Phaseoleae, Sophoreae, Swartzieae e Tephrosieae. Revista Brasileira de Botânica 24:85-97.

PAULA, A. de, SILVA, A.F. da, JÚNIOR, P.de M., SANTOS, F.A.M. dos \& SOUZA, A.L. de 2004. Sucessão ecológica da vegetação arbórea em uma Floresta Estacional Semidecidual, Viçosa, MG, Brasil. Acta Botanica Brasilica 18:407-423.

PARRA, P. 1984. Estúdio de la morfologia externa de plântulas de Calliandra gracilis, Mimosa albina, Mimosa arenosa, Mimosa camporum y Mimosa tenuiflora. Revista de la Facultad de Agronomia (Maracay) 13:311-350.

PINHEIRO, A.L., RAMALHO, R.S., VIDAL, W.N. \& VIDAL, M.R.R. 1989. Estudos dendrológicos com vistas à regeneração natural de Meliaceae na microrregião de Viçosa. Identificação e descrição de dez espécies. Revista Árvore 13:1-66.

RESSEL, K., GUILHERME, F.A.G., SCHIAVINI, I. \& OLIVEIRA, P.E. 2004. Ecologia morfofuncional de plântulas de espécies arbóreas da Estação Ecológica do Panga, Uberlândia, Minas Gerais. Revista Brasileira de Botânica 27:311-323. 
RICARDI, M., TORRES, F., HERNÁNDEZ, C. \& QUINTERO, R. 1977. Morfologia de plântulas de arboles venezolanos. I. Revista Florestal Venezolana 27:15-56.

SILVA, M.F., GOLDMAN, G.H., MAGALHÃES, F.M. \& MOREIRA, F.W. 1988. Germinação natural de 10 espécies arbóreas da Amazônia - I. Acta Amazônica 18:9-26.

SOUZA, L.A. 2003. Morfologia e anatomia vegetal (célula, tecidos, órgãos e plântula.) Editora da Universidade Estadual de Ponta Grossa, Ponta Grossa.

SOUZA, L.A. de \& OLIVEIRA, J.H.G. de 2004. Morfologia e anatomia das plântulas de Tabebuia avellanedae Lor. ex Griseb e T. chrysotricha (Mart. ex Dc.) Standl. (Bignoniaceae). Acta Scientiarum. Biological Sciences 26:217-226.
SOUZA, V.C. \& LORENZI, H. 2005. Botânica sistemática: Guia ilustrado para identificação das famílias de Angiospermas da flora brasileira. Nova Odessa, São Paulo.

STRASBURGER, E., NOLL, F., SCHENCK, H., \& SCHIMPER, A.F.W. 1953. Tratado de Botânica. Manuel Marin, Provenza Barcelona.

VAN SETTEN, A.K. \& KOEK-NOORMAN, J. 1986. Studies in Annonaceae VI. A leaf anatomical survey of genera of Annonaceae in Neotropics. Botanische Jahrbücher für Systematische, Pflanzengeschichte und Pflanzengeographie 108:17-50.

WATSON, L. \& DALLWITZ, M.J. 2000. The families of flowering plants: descriptions, illustrations, identification and information retrieval. Disponível em http:// biodiversity.uno.edu/delta. Acesso em 01/12/2005. 